\title{
Características anatômicas de mudas de morangueiro micropropagadas com diferentes fontes de silício
}

\author{
Francyane Tavares Braga( ${ }^{(1)}$, Claudinéia Ferreira Nunes(1), Ana Carolina Favero(1), Moacir Pasqual(1), \\ Janice Guedes de Carvalho ${ }^{(2)}$ e Evaristo Mauro de Castro $^{(3)}$
}

\begin{abstract}
(1)Universidade Federal de Lavras (Ufla), Departamento de Agricultura, Caixa Postal 37, CEP 37200-000 Lavras, MG. E-mail: ftbraga@yahoo.com.br, nunescfr@yahoo.com.br, acfavero@yahoo.com.br, mpasqual@ufla.br ${ }^{(2)}$ Ufla, Departamento de Ciências do Solo. E-mail: janicegc@ufla.br ${ }^{(3)} \bigcup f l a$, Departamento de Biologia. E-mail: emcastro@ufla.br
\end{abstract}

Resumo - O objetivo deste trabalho foi avaliar o efeito de diferentes fontes de silício, utilizadas na micropropagação, nas características anatômicas de mudas de morangueiro (Fragaria x ananassa). Foram utilizados propágulos da cv. Oso Grande cultivados em meio Murashige e Skoog (MS), acrescido de $30 \mathrm{~g} \mathrm{~L}^{-1}$ de sacarose, $6 \mathrm{~g} \mathrm{~L}^{-1}$ de ágar e $1 \mathrm{mg} \mathrm{L}^{-1}$ de 6-benzilaminopurina. Os tratamentos consistiram da adição ao meio MS dos silicatos de cálcio, de sódio e de potássio, na dosagem de $1 \mathrm{~g} \mathrm{~L}^{-1}$. O tratamento testemunha foi o meio MS sem fonte de silício. O delineamento experimental foi o inteiramente ao acaso, com dez repetições. Os propágulos foram mantidos por 45 dias em sala de crescimento, em condições controladas. Avaliaram-se características fitotécnicas e anatômicas dos propágulos in vitro. Verificou-se que o aumento da massa de matéria fresca e seca dos propágulos de morangueiro ocorreu na presença de silicato de sódio. A suplementação do meio de cultura com silício proporcionou maior teor de clorofila. A adição de silicato de sódio ao meio MS resultou em aumento da espessura dos tecidos do limbo foliar e da deposição de cera epicuticular e na formação de depósito de silício nas células.

Termos para indexação: Fragaria $x$ ananassa, cera epicuticular, micropropagação in vitro, silicato.

\section{Anatomical characteristics of the strawberry seedlings micropropagated using different sources of silicon}

\begin{abstract}
The objective of this work was to evaluate the effect of different silicon sources, used in micropropagation, on the anatomical characteristics of strawberry's (Fragaria $x$ ananassa) seedlings. Propagules of cv. Oso Grande were cultivated on a Murashige and Skoog (MS) medium containing $30 \mathrm{~g} \mathrm{~L}^{-1}$ of sucrose, $6 \mathrm{~g} \mathrm{~L}^{-1}$ of agar and $1 \mathrm{mg} \mathrm{L}^{-1}$ of 6-benzylamino purine. The treatments consisted of calcium, sodium, or potassium silicates added to the MS medium, at the dosage of $1 \mathrm{~g} \mathrm{~L}^{-1}$. The MS medium without added silicon was the check treatment. The experimental design was completely randomized with ten replications. The propagules were maintained during 45 days in a growth chamber, under controlled conditions. Developmental and anatomical characteristics of the in vitro propagules were evaluated. Fresh and dry weight of the propagules increased in the presence of sodium silicate. The supplementation of the culture medium with silicon increased the content of chlorophyll. The addition of sodium silicate in the MS medium resulted in increased thickness of leaf tissues and epicuticular wax deposition and in increased silicon deposit in the cells.
\end{abstract}

Index terms: Fragaria x ananassa, epicuticular wax, in vitro micropropagation, silicate.

\section{Introdução}

Novos patamares de produtividade do morangueiro têm sido atingidos como resultado da limpeza viral por meio de cultura de tecidos. As viroses podem ser causadas por um único vírus ou por um complexo de vírus, destacando-se os vírus do mosqueado, da clorose marginal, da faixa das nervuras, do encrespamento e do ondulado (Secchi, 1992). Plantas matrizes isentas de vírus, utilizadas na produção comercial de mudas, são obtidas pelo isolamento e cultivo de meristemas
(Calvete et al., 2000). O emprego da cultura de meristemas e propagação rápida in vitro possibilitou a produção, em larga escala, de plantas livres de vírus para uso em pesquisas e para fornecimento a viveiristas e a produtores de morango.

A composição do meio de cultura tem importante função nas respostas de crescimento de células e tecidos. Plantas ou explantes cultivados in vitro têm exigências nutricionais específicas e requerem meios nutritivos compostos por minerais, vitaminas e fontes de energia. Os meios de cultura podem ser modificados 
de acordo com a necessidade de cada tipo de explante e a espécie com a qual se esteja trabalhando (Torres et al., 2001).

Por não ser considerado um elemento essencial às plantas, o silício ( $\mathrm{Si}$ ) não tem sido muito estudado na micropropagação de plantas. Contudo, do ponto de vista fisiológico, para o crescimento e o desenvolvimento das plantas, o silício tem demonstrado efeito benéfico sobre o aumento de produção de diversas culturas (Gomes et al., 2008). Acredita-se que ele possa interferir na arquitetura das plantas e favorecer a fotossíntese, ao proporcionar folhas mais eretas, que têm maior eficiência fotossintética.

O silício tende a se acumular nas folhas, onde forma uma barreira protetora e regula a perda de água da planta por evapotranspiração. Isto auxilia a aclimatização das plantas micropropagadas, pois a principal causa de mortalidade durante esse processo é a perda de água, pela baixa funcionalidade dos estômatos e delgada camada de cera epicuticular (Silva, 2007).

O objetivo deste trabalho foi avaliar o efeito de diferentes fontes de silício, utilizadas na micropropagação, nas características anatômicas de mudas de morangueiro, visando a melhor qualidade das mudas.

\section{Material e Métodos}

O material vegetal utilizado foi fornecido pela empresa Multiplanta - Tecnologia Vegetal, e consistiuse de propágulos de morangueiro com aproximadamente $2 \mathrm{~cm}$ e uma a duas gemas, oriundos do terceiro subcultivo da cv. Oso Grande, pré-estabelecidos in vitro. O material foi subcultivado em meio MS (Murashige \& Skoog, 1962), suplementado com $30 \mathrm{~g} \mathrm{~L}^{-1}$ de sacarose e $1 \mathrm{mg} \mathrm{L}^{-1}$ de 6-benzilaminopurina (BAP).

Foram testados os silicatos de cálcio $\left(\mathrm{CaSiO}_{3}\right)$, de sódio $\left(\mathrm{Na}_{2} \mathrm{SiO}_{3}\right)$ e de potássio $\left(\mathrm{K}_{2} \mathrm{SiO}_{3}\right)$ como fontes de silício, na dosagem de $1 \mathrm{~g} \mathrm{~L}^{-1}$. O meio MS padrão foi usado como testemunha. Adicionaram-se $30 \mathrm{~g} \mathrm{~L}^{-1}$ de sacarose, $6 \mathrm{~g} \mathrm{~L}^{-1}$ de ágar e $1 \mathrm{mg} \mathrm{L}^{-1}$ de BAP ao meio. $\mathrm{O}$ pH do meio foi ajustado para 5,8 , antes da autoclavagem a $121^{\circ} \mathrm{C}$ e $1,2 \mathrm{~atm}$, durante $20 \mathrm{~min}$.

Posteriormente, em câmara de fluxo laminar, os propágulos foram inoculados, individualmente, em frascos de $200 \mathrm{~mL}$, com $30 \mathrm{~mL}$ do meio de cultivo MS modificado de acordo com o tratamento. Os frascos foram fechados com tampas de polipropileno e vedados com parafilme. As culturas foram mantidas em sala de crescimento a $25 \pm 2^{\circ} \mathrm{C}$, irradiância de $36 \mu \mathrm{mol} \mathrm{m}^{-2} \mathrm{~s}^{-1}$, fornecida por lâmpadas fluorescentes brancas de $20 \mathrm{~W}$, e fotoperíodo de 16 horas.

Após 45 dias, os propágulos foram avaliados com base nas seguintes características: número de folhas, matéria fresca e seca, conteúdo de água, teores de clorofila $a, b$, total e razão $a / b$, de acordo com o protocolo estabelecido por Arnon (1949), e as seguintes características anatômicas: deposição de silício na cera epicuticular da superfície adaxial da folha (características paradérmicas) em microscopia eletrônica de varredura, segundo protocolo de Alves (2004); espessuras das epidermes abaxial e adaxial, parênquimas paliçádico e esponjoso (características de limbo foliar) em microscopia de luz, segundo protocolo de Kraus \& Arduin (1997).

O delineamento experimental foi o inteiramente ao acaso, com dez repetições, cada uma composta por um frasco com cinco propágulos. Os dados foram submetidos à análise de variância e as médias foram comparadas pelo teste de Tukey, a 5\% de probabilidade.

\section{Resultados e Discussão}

Maior número de folhas e massa de matéria fresca e seca foram observados nos tratamentos $\mathrm{MS}+\mathrm{Na}_{2} \mathrm{SiO}_{3}$ e MS, que não diferiram estatisticamente entre si (Tabela 1). Diferentemente dos resultados deste trabalho, Silva (2007), ao trabalhar com gérbera (Gerbera jamesonii) in vitro, verificou maior número de folhas ao utilizar $\mathrm{CaSiO}_{3}$. Em tomateiro, Lana et al. (2003), ao utilizar doses crescentes de $\mathrm{CaSiO}_{3}$ no solo, não verificaram efeito positivo na produtividade.

Zhou (1995) verificou aumento de tamanho das folhas de Phalaenopsis com o cultivo em concentrações

Tabela 1. Número de folhas (NF), massa de matéria fresca (MMF), massa de matéria seca (MMS) e conteúdo de água (CA) da parte aérea de morangueiro micropropagado com diferentes fontes de silício em meio Murashige \& Skoog (MS) ${ }^{(1)}$.

\begin{tabular}{lrccc}
\hline Fonte de silício & NF & MMF (g) & MMS (g) & CA (\%) \\
\hline $\mathrm{MS}$ & $9 \mathrm{a}$ & $2,00 \mathrm{a}$ & $0,23 \mathrm{a}$ & $88,56 \mathrm{a}$ \\
$\mathrm{MS}+\mathrm{CaSiO}_{3}$ & $6 \mathrm{~b}$ & $1,15 \mathrm{~b}$ & $0,15 \mathrm{a}$ & $86,08 \mathrm{~b}$ \\
$\mathrm{MS}+\mathrm{Na}_{2} \mathrm{SiO}_{3}$ & $10 \mathrm{a}$ & $2,03 \mathrm{a}$ & $0,26 \mathrm{a}$ & $86,83 \mathrm{~b}$ \\
$\mathrm{MS}+\mathrm{K}_{2} \mathrm{SiO}_{3}$ & $7 \mathrm{~b}$ & $1,90 \mathrm{a}$ & $0,23 \mathrm{a}$ & $87,84 \mathrm{a}$ \\
\hline
\end{tabular}

${ }^{(1)}$ Médias seguidas de letras iguais não diferem entre si pelo teste de Tukey, a $5 \%$ de probabilidade. 
de $0,1-1,0 \mathrm{mg} \mathrm{L}^{-1}$ de $\mathrm{CaSiO}_{3}$ adicionado ao meio de cultura. Essa diferença de resultados pode ser explicada pelo fato de o crescimento de plantas, órgãos, tecidos e células in vitro depender do desenvolvimento de meios de cultura otimizados para cada espécie e pela perfeita interação de componentes essenciais como fontes de carbono e nutrientes minerais.

Maior concentração de clorofila $a$ foi registrada no tratamento $\mathrm{MS}+\mathrm{K}_{2} \mathrm{SiO} 3$, enquanto as maiores concentrações de clorofila $b$ e total foram registradas no tratamento $\mathrm{MS}+\mathrm{Na}_{2} \mathrm{SiO}_{3}$ (Tabela 2). Mesmo não tendo apresentado diferença significativa entre os tratamentos, exceto para $\mathrm{MS}+\mathrm{Na}_{2} \mathrm{SiO}_{3}$, maior relação clorofila $a / b$ foi observada no meio MS sem silício. Entre os efeitos verificados por Adatia \& Besford (1986) e Epstein (2001), o uso de uma fonte de silicato foi capaz de aumentar o teor de clorofila das folhas e a tolerância das plantas aos estresses ambientais, como frio, calor, seca, desbalanço nutricional e toxicidade a metais, além de reforçar a parede celular e aumentar a resistência a patógenos e insetos. Tais resultados demonstram os benefícios do uso de uma fonte de silício na micropropagação do morangueiro, principalmente quanto a aparatos fotossintéticos, como maior nível de clorofila e massa foliar.

Quanto às características anatômicas, o limbo foliar apresentou epidermes unisseriadas, parênquima paliçádico dorsiventral multisseriado. Nos tratamentos $\mathrm{MS}+\mathrm{CaSiO}_{3}, \mathrm{MS}+\mathrm{Na}_{2} \mathrm{SiO}_{3}$ e $\mathrm{MS}$ o limbo está com duas camadas de células paliçádicas e no tratamento $\mathrm{MS}+\mathrm{K}_{2} \mathrm{SiO}_{3}$, com três camadas de células paliçádicas (Figura $1 \mathrm{~A}$ ). O parênquima esponjoso apresentou espaços intercelulares característicos de folhas cultivadas em ambientes in vitro. Observaram-se depósitos de silício próximos à epiderme, no tratamento com $\mathrm{MS}+\mathrm{Na}_{2} \mathrm{SiO}_{3}$ (Figura 2).

Tabela 2. Teores de clorofila $a, b$, total e razão $a / b$ de folhas de morangueiro micropropagado com diferentes fontes de silício em meio Murashige \& Skoog (MS $)^{(1)}$.

\begin{tabular}{lcrrr}
\hline Fonte de silício & \multicolumn{4}{c}{ Clorofila $\left(\mu \mathrm{g} \mathrm{mL}^{-1}\right)$} \\
\cline { 2 - 5 } & \multicolumn{1}{c}{$\mathrm{a}$} & \multicolumn{1}{c}{$\mathrm{b}$} & \multicolumn{1}{c}{ Total } & $\mathrm{a} / \mathrm{b}$ \\
\hline $\mathrm{MS}$ & $8,74 \mathrm{c}$ & $2,71 \mathrm{c}$ & $11,50 \mathrm{c}$ & $3,86 \mathrm{a}$ \\
$\mathrm{MS}+\mathrm{CaSiO}_{3}$ & $6,74 \mathrm{~d}$ & $2,30 \mathrm{c}$ & $9,05 \mathrm{~d}$ & $2,94 \mathrm{a}$ \\
$\mathrm{MS}+\mathrm{Na}_{2} \mathrm{SiO}_{3}$ & $10,56 \mathrm{~b}$ & $12,41 \mathrm{a}$ & $22,86 \mathrm{a}$ & $0,84 \mathrm{~b}$ \\
$\mathrm{MS}+\mathrm{K}_{2} \mathrm{SiO}_{3}$ & $11,52 \mathrm{a}$ & $4,80 \mathrm{~b}$ & $16,32 \mathrm{~b}$ & $2,40 \mathrm{a}$ \\
\hline
\end{tabular}

${ }^{(1)}$ Médias seguidas de letras iguais não diferem entre si pelo teste de Tukey, a $5 \%$ de probabilidade.
Pela análise anatômica de uma folha, é possível demonstrar a presença de depósitos de silício, comumente chamados de silicofitólitos, que ocorrem na parede celular como incrustação e/ou impregnação, ou ainda, sob a forma de corpos silicosos (opala) no interior das células de diferentes tecidos (Metcalfe, 1983).

Quanto à espessura dos tecidos foliares, houve diferenças estatísticas para todas as variáveis analisadas (Tabela 3).

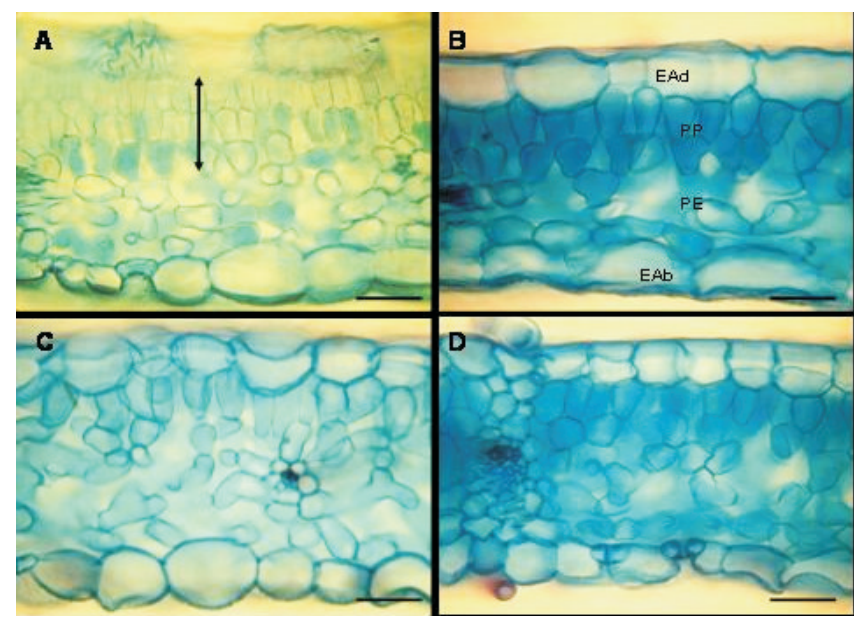

Figura 1. Fotomicrografias de secções transversais de folhas de morangueiro cultivadas in vitro com diferentes fontes de silício. A, Murashige \& Skoog (MS) $+\mathrm{K}_{2} \mathrm{SiO}_{3}$; $\mathrm{B}, \mathrm{MS}+\mathrm{CaSiO}_{3} ; \mathrm{C}, \mathrm{MS}+\mathrm{Na}_{2} \mathrm{SiO}_{3} ; \mathrm{D}, \mathrm{MS}$. EAd, epiderme adaxial; PP, parênquima paliçadico; PE, parênquima esponjoso; EAb, epiderme abaxial. Seta, tripla camada de células do parênquima paliçádico. Barra $=40 \mu \mathrm{m}$.

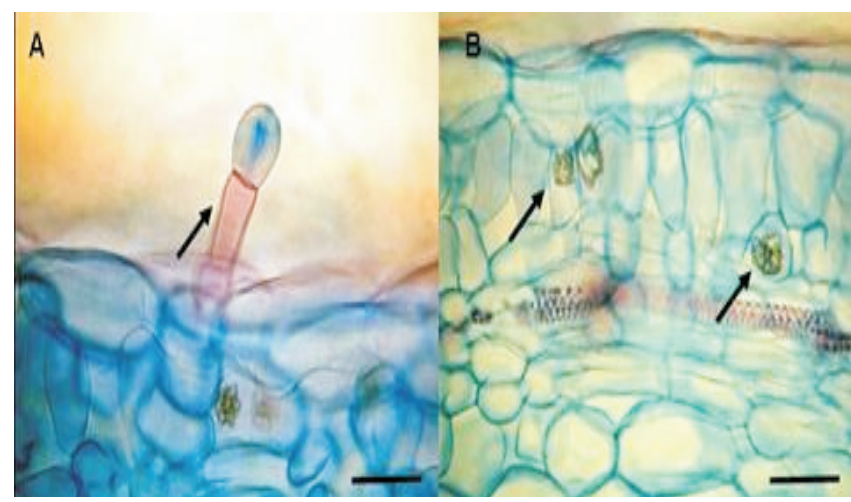

Figura 2. Fotomicrografias de secções transversais de folhas de morangueiro cultivadas in vitro com silicato de sódio. Presença de tricoma glandular captado (A) e depósito de silício (setas) (B). Barra $=40 \mu \mathrm{m}$. 
As epidermes abaxial e adaxial, o parênquima esponjoso e o mesofilo apresentaram maior espessura no tratamento $\mathrm{MS}+\mathrm{Na}_{2} \mathrm{SiO}_{3}$. Melhor resultado para parênquima paliçádico foi obtido no tratamento $\mathrm{MS}+\mathrm{K}_{2} \mathrm{SiO}_{3}$, o que era esperado, pois apresentou três camadas de células paliçádicas e menor preenchimento do mesofilo com parênquima esponjoso, em relação aos demais tratamentos. Resultados distintos foram obtidos por Calvete et al. (2002), que, ao trabalhar com morangueiro da cv. Vila Nova, observaram espessura de parênquima paliçádico inferior e com apenas uma camada de células em propágulos cultivados in vitro, em relação às plantas ex vitro, em que os autores observaram duas camadas de células desse mesmo tecido. Maior espessura desses tecidos do limbo foliar confere à planta cultivada in vitro maior possibilidade de sobrevivência durante a transferência para ambiente ex vitro, o que é um fator importante para o sucesso da cultura de tecidos (Barboza et al., 2006; Silva et al., 2008).

$\mathrm{Na}$ caracterização da superfície foliar, maior deposição de cera epicuticular foi visualizada na epiderme adaxial das folhas de morangueiro submetidas a tratamento com diferentes fontes de silício, em relação ao tratamento testemunha (Figura 3). Observaram-se, também, dois tipos de tricomas: tectores e glandulares captados. Tais características não foram encontradas por Calvete et al. (2002), que registraram apenas a presença de tricomas tectores em morangueiro cultivado in vitro.

$\mathrm{Na}$ epiderme foliar, o silício combina com a celulose (Silva et al., 2005) e pode estar presente nas célulasguarda dos estômatos e nos tricomas. Segundo esses autores, o silício também pode ser encontrado nos elementos vasculares. A deposição desse elemento na parede das células torna a planta mais resistente à ação de fungos e insetos, evita a perda excessiva de água e diminui a taxa de transpiração (Silva, 2007), o que poderá elevar a taxa de sobrevivência durante o processo de aclimatização.

Tabela 3. Espessura dos tecidos do limbo foliar de morangueiro micropropagado com diferentes fontes de silício em meio Murashige \& Skoog (MS $)^{(1)}$.

\begin{tabular}{lccccc}
\hline $\begin{array}{l}\text { Fonte de } \\
\text { silício }\end{array}$ & $\begin{array}{c}\text { EAb } \\
(\mu \mathrm{m})\end{array}$ & $\begin{array}{c}\text { EAd } \\
(\mu \mathrm{m})\end{array}$ & $\begin{array}{c}\text { PE } \\
(\mu \mathrm{m})\end{array}$ & $\begin{array}{c}\text { PP } \\
(\mu \mathrm{m})\end{array}$ & $\begin{array}{c}\text { Mesofilo } \\
(\mu \mathrm{m})\end{array}$ \\
\hline $\mathrm{MS}$ & $19,80 \mathrm{c}$ & $27,60 \mathrm{a}$ & $68,70 \mathrm{~b}$ & $22,20 \mathrm{~d}$ & $90,90 \mathrm{~b}$ \\
$\mathrm{MS}+\mathrm{CaSiO}_{3}$ & $20,25 \mathrm{c}$ & $23,10 \mathrm{~b}$ & $38,70 \mathrm{c}$ & $44,85 \mathrm{a}$ & $83,55 \mathrm{~b}$ \\
$\mathrm{MS}+\mathrm{Na}_{2} \mathrm{SiO}_{3}$ & $31,95 \mathrm{a}$ & $29,01 \mathrm{a}$ & $94,17 \mathrm{a}$ & $34,65 \mathrm{c}$ & $128,82 \mathrm{a}$ \\
$\mathrm{MS}+\mathrm{K}_{2} \mathrm{SiO}_{3}$ & $26,26 \mathrm{~b}$ & $25,50 \mathrm{~b}$ & $67,05 \mathrm{~b}$ & $57,75 \mathrm{a}$ & $124,80 \mathrm{a}$ \\
\hline
\end{tabular}

${ }^{(1)}$ Médias seguidas de letras iguais não diferem entre si pelo teste de Tukey, a $5 \%$ de probabilidade; EAb, epiderme abaxial; Ead, epiderme adaxial; $\mathrm{PE}$, parênquima esponjoso; PP, parênquima paliçádico.

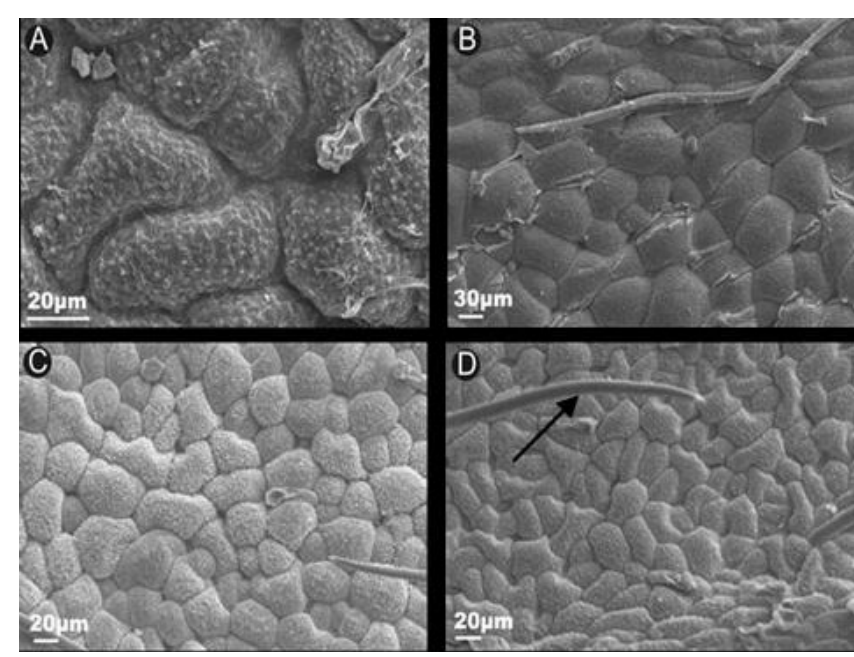

Figura 3. Eletromicrografia de folhas de morangueiro submetidas a diferentes fontes de silício no cultivo in vitro. A, Murashige \& Skoog (MS) $+\mathrm{K}_{2} \mathrm{SiO}_{3} ; \mathrm{B}, \mathrm{MS}+\mathrm{CaSiO}_{3}$; C, $\mathrm{MS}+\mathrm{Na}_{2} \mathrm{SiO}_{3} ; \mathrm{D}, \mathrm{MS}$. Seta, tricomas tectores.

\section{Conclusões}

1. O uso de silicato de sódio promove o aumento de matéria fresca e seca em propágulos micropropagados de morangueiro.

2. Maior teor de clorofila é obtido quando os propágulos do morangueiro são cultivados em meio MS suplementado com fonte de silício.

3. A adição de silicato de sódio ao meio de cultura resulta em aumento da espessura dos tecidos do limbo foliar e da deposição de cera epicuticular e na formação de depósito de silício nas células.

\section{Agradecimentos}

À Fundação deAmparoà Pesquisa do Estado deMinas Gerais, ao Conselho Nacional de Desenvolvimento Científico e Tecnológico e à Coordenação de Aperfeiçoamento de Pessoal de Nível Superior, pelo apoio financeiro recebido.

\section{Referências}

ADATIA, M.H.; BESFORD, R.T. The effects of silicon on cucumber plants grown in recirculating nutrient solution. Annals of Botany, v.58, p.343-351, 1986.

ALVES, E. Introdução à microscopia eletrônica. Lavras: Ufla/ Faepe, 2004. 88p. 
ARNON, D.I. Copper enzymes in isolated chloroplasts polyphenoloxidase in Beta vulgaris. Plant Physiology, v.24, p.1-15, 1949 .

BARBOZA, S.B.S.C.; GRACIANO-RIBEIRO, D.; TEIXEIRA, J.B.; PORTES, T.A.; SOUZA, L.A.C. Anatomia foliar de plantas micropropagadas de abacaxi. Pesquisa Agropecuária Brasileira, v.41, p.185-194, 2006.

CALVETE, E.O.; AZEVEDO, M.; BORDIGNON, M.H.; SUZIN, $\mathrm{M}$. Análises anatômicas e da biomassa em plantas de morangueiro cultivadas in vitro e ex vitro. Horticultura Brasileira, v.20, p.649-653, 2002.

CALVETE, E.O.; KÄMPF, A.N.; BERGAMASCHI, H.; DAUDT, R.H.S. Avaliação do crescimento de plantas de morangueiro, durante aclimatização ex vitro. Horticultura Brasileira, v.18, p.188-192, 2000.

EPSTEIN, E. Silicon in plants, facts vs. concepts. In: DATNOFF, L.E.; SNYDER G.H.; KORNDÖRFER, G.H. (Ed.). Silicon in agriculture. Amsterdam: Elsevier, 2001. p.1-15.

GOMES, F.B.; MORAES, J.C.; SANTOS, C.D. dos; ANTUNES, C.S. Uso de silício como indutor de resistência em batata a Myzus persicae (Sulzer) (Hemiptera: Aphididae). Neotropical Entomology, v.37, p.185-190, 2008.

KRAUS, J.E.; ARDUIM, M. Manual básico de métodos em morfologia vegetal. Seropédica: UFRRJ, 1997. 198p.

LANA, R.M.Q.; KORNDÖRFER, G.H.; ZANÃO JÚNIOR, L.A.; SILVA, A.F. da.; LANA, A.M.Q. Efeito do silicato de cálcio sobre a produtividade e acumulação de silício no tomateiro. Bioscience Journal, v.19, p.15-20, 2003.
METCALFE, C.R. Secretary mineral substances - silica. In: METCALFE, C.R.; CHALK, L. Anatomy of the dicotyledons. 2.ed. Oxford: Claredon, 1983. v.2. p.82-94.

MURASHIGE, T.; SKOOG, F. A revised medium for rapid growth and bio assays with tobacco tissue cultures. Physiologia Plantrarum, v.15, p.473-497, 1962.

SECCHI, V.A. Controle integrado de pragas e doenças do morangueiro. 3.ed. Porto Alegre: Emater-RS, 1992. 66p.

SILVA,A.B. da; PASQUAL, M.; CASTRO, E.M. de; MIYATA, L.Y.; MELO, L.A. de; BRAGA, F.T. Luz natural na micropropagação do abacaxizeiro (Ananas comosus L. Merr). Interciencia, v.33, p.839-843, 2008.

SILVA, D.P. Meios de cultura e fontes de silício no desenvolvimento in vitro de gérbera. 2007. 84p. Dissertação (Mestrado) - Universidade Federal de Lavras, Lavras.

SILVA, L.P. da; SILVA, L.S. da; BOHNEN, H. Componentes da parede celular e digestibilidade in vitro de palha de arroz (Oryza sativa) com diferentes teores de silício. Ciência Rural, v.35, p.1205-1208, 2005

TORRES, A.C.; BARBOSA, N.V. dos R.; WILLADINO, L.; GUERRA, M.P.; FERREIRA, C.F.; PAIVA, S.A.V. de. Meio e condições de incubação para a cultura de tecidos de plantas: formulações de meios de cultura de tecidos de plantas. Brasília: Embrapa Hortaliças, 2001. 19p. (Embrapa Hortaliças. Circular Técnica, 24).

ZHOU, T.S. The detection of the accumulation of silicon in Phalaenopsis (Orchidaceae). Annals of Botany, v.75, p.605-607, 1995.

Recebido em 4 de novembro de 2008 e aprovado em 30 de janeiro de 2009 